\title{
Potentiation of paclitaxel cytotoxicity in lung and esophageal cancer cells by pharmacologic inhibition of the phosphoinositide 3-kinase/protein kinase B (Akt)-mediated signaling pathway
}

Dao M. Nguyen, MD, MSc, FRCSC, FACS

G. Aaron Chen, MS

Rishindra Reddy, MD

Wilson Tsai, MD

William D. Schrump

George Cole, Jr, MD

David S. Schrump, MD, FACS

From the Section of Thoracic Oncology, Surgery Branch, Center for Cancer Research, National Cancer Institute, National Institutes of Health, Bethesda, Md.

Read at the Eighty-third Annual Meeting of The American Association for Thoracic Surgery, Boston, Mass, May 4-7, 2003.

Received for publication May 2, 2003; revisions requested Aug 28, 2003; accepted for publication Sept 9, 2003.

Address for reprints: Dao M. Nguyen, MD, MSc, FRCSC, FACS, Section of Thoracic Oncology, Room 2B07, Building 10, 10 Center Drive, Bethesda, MD (E-mail: Dao_Nguyen@nih.gov).

J Thorac Cardiovasc Surg 2004;127:365-75 0022-5223/ $\$ 30.00$

Copyright $\odot 2004$ by The American Association for Thoracic Surgery

doi:10.1016/j.jtcvs.2003.09.033
Background: Constitutive activation of the phosphoinositide 3-kinase/protein kinase B survival signal transduction pathway influences the intrinsic chemoresistance of cancer cells. This study evaluates the effect of LY294002, a pharmacologic inhibitor of phosphoinositide 3-kinase, on the sensitivity of lung and esophageal cancer cells to paclitaxel (Taxol) in vitro.

Materials and Methods: Cell viability and apoptosis of cancer cells treated with paclitaxel + LY294002 combinations were quantitated by methyl-thiazol-diphenyltetrazolium and terminal deoxynucleotidyltransferase-mediated dUTP nick-end labeling-based ApoBrdU assays, respectively. The effect of LY294002-mediated phosphoinositide 3-kinase inhibition on protein kinase B (Akt) activation and nuclear factor- $\kappa \mathrm{B}$ signaling was determined by Western blot analysis. Nuclear factor- $\kappa \mathrm{B}$ transcription activity in cultured cancer cells either at baseline or after treatments with LY294002 or BAY11-0782 (a pharmacologic inhibitor of nuclear factor $-\kappa \mathrm{B}$ ) was determined by the nuclear factor- $\kappa \mathrm{B}$-Luciferase reporter system.

Results: A 4- to more than 20-fold reduction of paclitaxel $\mathrm{IC}_{50}$ values was observed in cancer cells treated with paclitaxel + LY294002 combinations. This was paralleled with synergistic induction of apoptosis. LY294002 treatment caused a significant dose-dependent inhibition of protein kinase B (Akt) activation and suppression of nuclear factor- $\kappa \mathrm{B}$ transcriptional activity that was accompanied by elevation of $\mathrm{I} \kappa \mathrm{B}$, the intrinsic inhibitor of nuclear factor $-\kappa \mathrm{B}$, and concomitant reduction of nuclear factor- $\kappa \mathrm{B}-$ regulated antiapoptotic proteins cIAP1, cIAP2, and BclXL. Direct inhibition of nuclear factor- $\kappa \mathrm{B}$ activity by BAY11-0782 also resulted in profound enhancement of paclitaxel sensitivity and paclitaxel-mediated induction of apoptosis in lung and esophageal cancer cells.

Conclusion: LY294002-mediated inhibition of the phosphoinositide 3-kinase/protein kinase B-dependent survival pathway with secondary suppression of nuclear factor $-\kappa \mathrm{B}$ transcriptional activity was associated with enhancement of paclitaxel cytotoxicity in lung and esophageal cancer cells. Direct inhibition of nuclear factor- $\kappa$ B by BAY11-0782 also sensitized these cancer cells to paclitaxel, indicating that nuclear factor- $\kappa \mathrm{B}$ may be the crucial intermediary step connecting phosphoinositide 3-kinase/protein kinase B (Akt) to the intrinsic susceptibility of cancer cells to chemotherapeutic agents. 


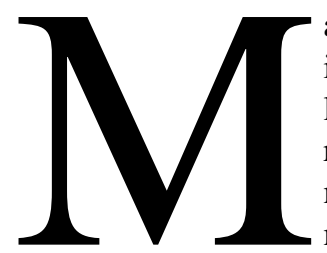

alignant tumors of epithelial origin, including those originating from the lung or the esophagus, are generally refractory to current cytotoxic chemotherapeutic agents. This poses a major therapeutic dilemma for the majority of patients with lung or esophageal cancers because they frequently present with locally advanced or metastatic disease for which chemotherapy or radiation is the only treatment option. Chemotherapy, at best, provides symptomatic relief of cancer symptoms and improves quality of life with marginal prolongation of survival for a few months in patients with stage IV lung or esophageal cancers. $^{1,2}$

The molecular basis of chemoresistance in malignant cells is incompletely understood and seems to involve complex interactions of both genetic and epigenetic factors. Detailed molecular analysis of growth factor signal transduction pathways, exemplified by studies of members of the epidermal growth factor receptor (EGFR) superfamily, that is, HER2/neu or EGFR, has shown their roles in the process intrinsic chemoresistance of cancer cells. ${ }^{2}$ Of significant importance is the identification of the intracellular signaling pathways governed by phosphoinositide 3-kinase (PI3K) as the cell survival pathways and their roles in protecting cells against cytotoxic stress. ${ }^{3}$ PI3K activation is initiated, and thus controlled, by growth factors through activation of their cognate membrane receptors. Schematic presentation of growth factor-induced activation of PI3K and its downstream targets is shown in Figure 1. Phosphorylation of the growth factor receptors subsequent to binding of growth factors allows recruitment of adaptor molecules such as SOS and Grb2. PI3K translocates to the membrane and is activated by either direct binding to phosphorylated receptors or adaptor molecules. PI3K phosphorylates the cell membrane phosphatidylinositol lipids to form phosphatidylinositol-3,4,5-triphosphate $\left(\mathrm{PIP}_{3}\right)$. $\mathrm{PIP}_{3}$ attracts protein kinase $\mathrm{B}$ (Akt) and 3' phosphoinositide-dependent kinase 1 (PDK1) to the cell membrane and brings them to physical proximity where Akt is phosphorylated and activated by PDK1. Activated Akt in turn phosphorylates and modulates the function of a myriad of cellular proteins resulting in an antiapoptotic milieu that enables activated cells to survive cytotoxic stress. ${ }^{3,4}$ Functional inhibition of PI3K or Akt in malignant cells should decrease their survival capacity and increase their susceptibility to the cytotoxic effects of chemotherapeutic agents. ${ }^{4-9}$

This study determined whether blocking PI3K function by the pharmacologic agent LY294002 (LY) could inhibit Akt activation and sensitize cultured lung and esophageal cancer cells to the cytotoxic effect of paclitaxel (Taxol). Because Akt signaling is directly linked to the survival transcription factor nuclear factor (NF)- $\kappa \mathrm{B}$ through the $\mathrm{I} \kappa \mathrm{K} /$
$\mathrm{I} \kappa \mathrm{B}$ complex, we questioned whether LY-mediated PI3K inhibition also suppresses the transcription activity of NF$\kappa \mathrm{B}$, which may in turn act as the intermediary step of the chemosensitization effect of this compound. To directly address this issue, intrinsic cellular NF- $\kappa \mathrm{B}$ activity of cultured lung and esophageal cancer cells was directly inhibited by the I $\kappa \mathrm{K}$ inhibitor BAY11-7082 (BAY), ${ }^{10}$ and treated cells were assessed for their responsiveness to paclitaxel cytotoxicity.

\section{Materials and Methods \\ Cells and Reagents}

Non-small cell lung cancer (NSCLC) cells H460, H226, and H322 and esophageal cancer cells SKGT5, HCE4, and TE2 were maintained in Roswell Park Memorial Institute (RPMI) 1460 culture medium supplemented with streptomycin $(100 \mu \mathrm{g} / \mathrm{mL})$ and penicillin $(100 \mathrm{U} / \mathrm{mL})$, glutamine ( $2 \mathrm{mmol} / \mathrm{L})$, and $10 \%$ (vol/vol) fetal calf serum (complete medium). LY and BAY were purchased from Sigma (St Louis, Mo) and Alexis Corp (San Diego, Calif), respectively. They were dissolved in dimethyl sulfoxide as $10-\mathrm{mmol} / \mathrm{L}$ stocks and stored at $-80^{\circ} \mathrm{C}$. Plasmid containing the Luciferase gene under the control of a promoter containing the NF- $\kappa \mathrm{B}$ binding consensus sequences (NF- $\kappa \mathrm{B}-\mathrm{Luc}$ ) (BD Biosciences Clontech, Palo Alto, Calif) and plasmid containing the $\beta$-galactosidase gene under the control of the Roux sarcoma virus promoter (RSV-LacZ) were purchased from Clontech (Palo Alto, Calif). Bacteria stocks containing the plasmids were amplified in LB broth under ampicillin selection, and plasmids were isolated using the $\mathrm{CsCl}$ technique. Methyl-thiazol-diphenyl-tetrazolium (MTT) was obtained from Sigma. Paclitaxel was purchased from Bristol-Myers-Squibb (Lawrenceville, NJ) through the pharmacy of the National Institutes of Health Clinical Center. Luciferase assay kits were obtained from Promega (Madison, Wis).

\section{Cell Proliferation and Apoptosis Assays}

Cancer cells were seeded in 96-well microtiter plates at predetermined cell densities $\left(5-10 \times 10^{3}\right.$ cells/well) for optimal results. After an overnight incubation to allow cells to attach to the bottom of the wells, the culture medium was removed and cells were treated with paclitaxel $(16-4000 \mathrm{nmol} / \mathrm{L}$ in serum-free RPMI medium) for 90 minutes. Cells were recultured in complete medium after paclitaxel treatment. Twelve hours later, they were treated with $\operatorname{LY}(10,20$, or $40 \mu \mathrm{mol} / \mathrm{L})$ or BAY $(10,20$, or $30 \mu \mathrm{mol} / \mathrm{L})$. Cell viability was evaluated by MTT assay at 72 hours after the onset of paclitaxel treatment. The sensitivity of tumor cells to paclitaxel (after paclitaxel treatment alone or in combination with $\mathrm{LY}$ or BAY) was determined by estimating the paclitaxel $\mathrm{IC}_{50}$ values (paclitaxel doses that induced 50\% growth inhibition) from the dose-response curves. Appropriate corrections were made to account for the mild growth inhibitory effect of LY or BAY when calculating paclitaxel $\mathrm{IC}_{50}$ values of cells treated with the drug combination. For apoptosis assays, NSCLC or esophageal cancer cells were seeded in 6-well tissue culture plates at $3 \times 10^{5}$ cells per well. They were then treated with the sequential paclitaxel + LY or paclitaxel + BAY combinations. Cells were harvested 60 hours after the onset of paclitaxel treatment, and apoptosis was quantitated using the terminal deoxynucleotide transferase-mediated 


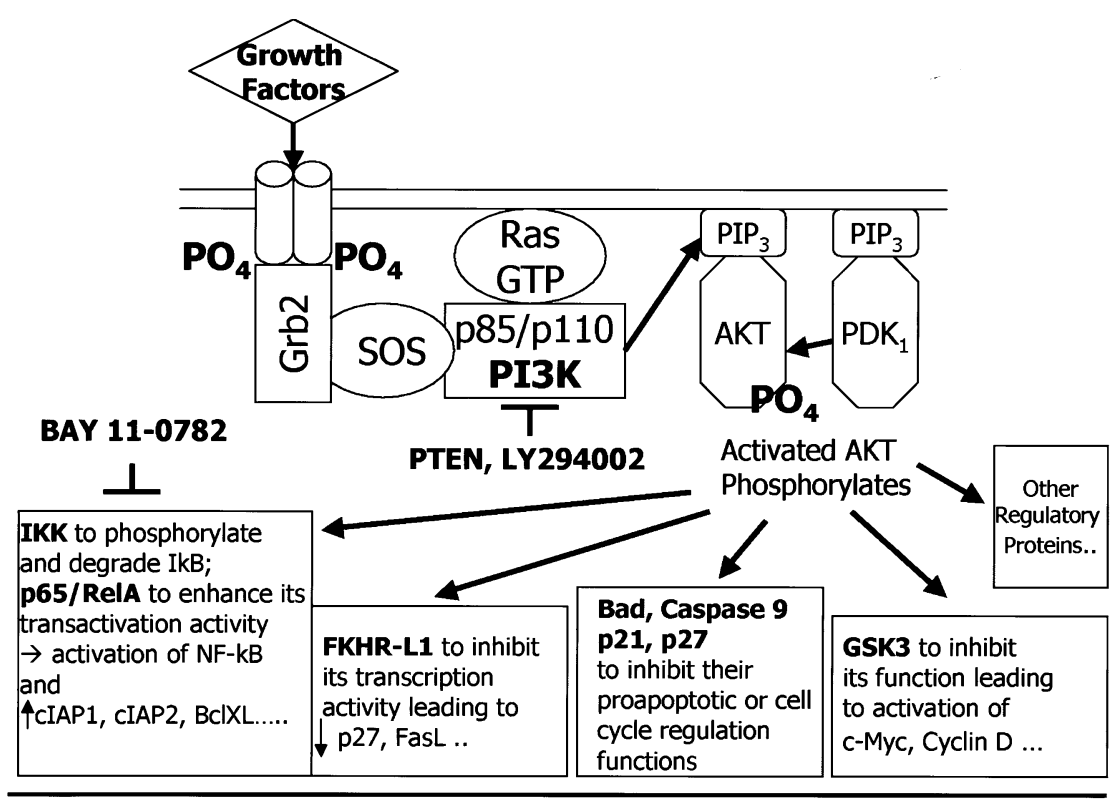

All Contributes to Enhanced Survival Capability

Figure 1. Downstream signaling of activated Akt. Binding of growth factors to their cognate receptors results in receptor phosphorylation, recruitment of multiple adaptor proteins (SOS and Grb2), activation of PI3K, and generation of $\mathrm{PIP}_{3}$ in the plasma membrane. $\mathrm{PIP}_{3}$ provides docking sites for proteins containing the Pleckstrin homology domain (eg, Akt and PDK1) to accumulate at the sites of PI3K activation. Proximity of Akt and PDK results in phosphorylation and activation of Akt. Activated Akt in turn phosphorylates and modulates functions of a myriad of cellular proteins, creating an antiapoptotic milieu and enhanced cell-survival capacity. NF, Nuclear factor; $\boldsymbol{P I P}_{3}$, phosphatidylinositol-3,4,5-triphosphate.

dUTP nick-end labeling (TUNEL)-based ApoBrdU assay (BD Pharmingen, San Diego, Calif) according to the protocol provided by the manufacturer. To determine the growth inhibitory effect of LY, cells were similarly seeded in 96-well plates in complete medium and then continuously exposed to increasing concentrations of LY $(5-80 \mu \mathrm{mol} / \mathrm{L})$ for 60 hours, and cell viability was quantitated by MTT assay. The effect of LY treatment on cellcycle progression of cancer cells treated with LY (10 or 40 $\mu \mathrm{mol} / \mathrm{L}$ ) for either 24 hours or 48 hours was evaluated by propidium iodide staining, and flow cytometry was used to evaluate the effect of LY treatment $(10 \mu \mathrm{mol} / \mathrm{L}$ or $40 \mu \mathrm{mol} / \mathrm{L}$ for either 24 or 48 hours) on cell-cycle progression in cancer cells.

\section{NF-кB Transcription Activity Assay}

Cultured cancer cells were transiently transfected with NF- $\kappa$ B-Luc or RSV-LacZ plasmids using FuGene (Roche Diagnostics, Indianapolis, Ind) according to the protocol provided by the manufacturer. Luciferase activity, as measured by commercially available kits and a lucinometer (Perkin Elmer-Wallac, Westbury, NY) (normalized for protein content of cell lysates and the $\beta$-galactosidase activity serving as internal control for transduction efficiency), directly correlates with the levels of NF- $\kappa \mathrm{B}$ transcription activity. Transfected cells were treated with LY $(10,20$, or 40 $\mu \mathrm{mol} / \mathrm{L}$ ) for 18 hours, and Luciferase or $\beta$-galactosidase activities and cellular protein content bicinchoninic acid technique, Pierce Biotechnology, Inc, Rockford, Ill) were measured. Normalized
Luciferase activity of treated cells was then expressed as percentages of activity of untreated control cells.

\section{Western Blots}

NSCLC or esophageal cancer cells were treated with LY $(10,20$, or $40 \mu \mathrm{mol} / \mathrm{L}$ ) for 18 hours and harvested in Laemmli buffer. Cell lysates were immunoblotted using the standard Western blot technique with monoclonal antibodies recognizing phosphorylated and total Akt (Cell Signaling Technology, Beverly, Mass), I $\kappa$ B, cIAP-1, cIAP-2 (R\&D, Minneapolis, Minn), and BclXL (Upstate Biotechnology, Lake Placid, NY). Blots were also probed for $\beta$-actin (Oncogene Research Product, Cambridge, Mass) to verify equal loadings of proteins.

\section{Data Analysis}

Data are expressed as mean and SD for at least 3 independent experiments that yielded similar results. The student $t$ test was used for statistical analysis.

\section{Results}

LY-Mediated Growth Inhibition by Induction of CellCycle Arrest at the G0/G1 Checkpoint

Continuous exposure of NSCLC and esophageal cancer cells to LY resulted in a significant dose-dependent reduction of the levels of phosphorylated Akt (without altering 


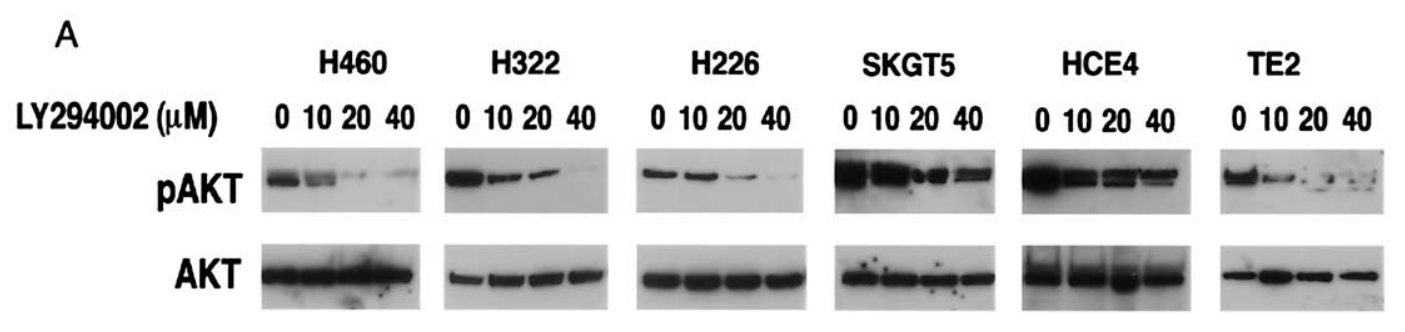

B
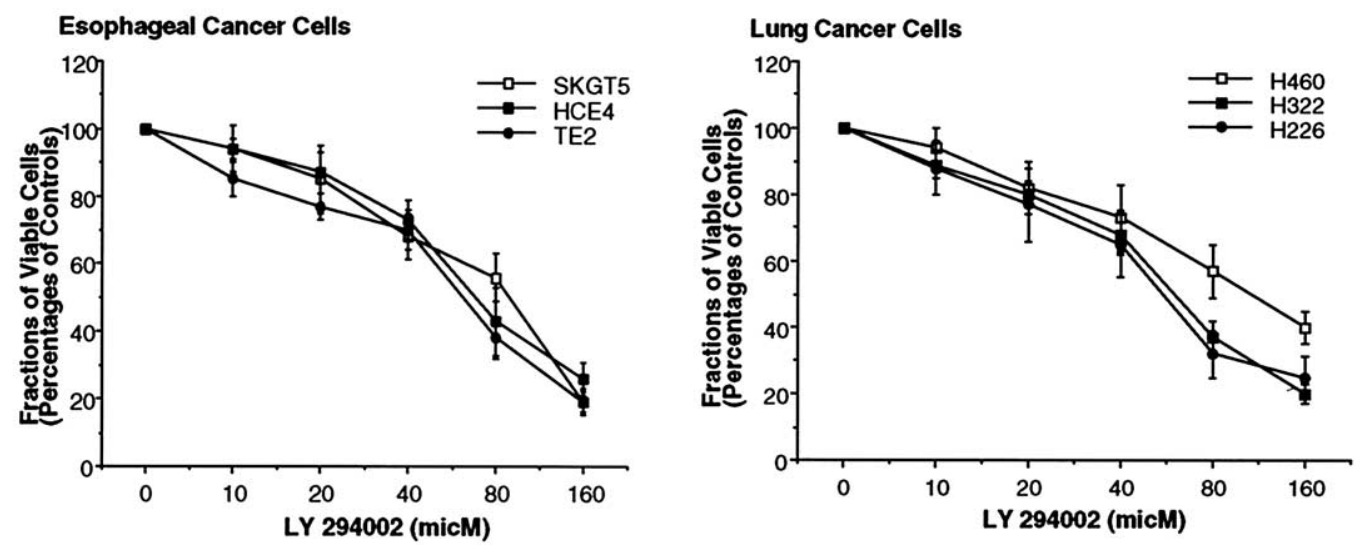

Figure 2. A, Western blot analysis of LY-mediated dose-dependent suppression of Akt phosphorylation in NSCLC and esophageal cancer cell lines in vitro. B, Dose-dependent inhibition of cell proliferation by LY in NSCLC and esophageal cancer cells. Cells were treated with increasing concentrations of LY for 60 hours, and viable cells were quantitated by MTT assay. Data are presented as mean \pm SD of 3 independent experiments.

the total Akt levels) that was correlated with inhibition of cell proliferation in vitro (Figure 2, $A$ and $B$ ). Cell-cycle analysis indicated that LY treatment caused a dose-dependent and treatment duration-dependent accumulation of cells at the G0/G1 phase with a corresponding reduction of cells in the $\mathrm{S}$ and $\mathrm{G} 2 / \mathrm{M}$ phases of the cell cycle, compatible with cell arrest at the G1/S checkpoint as shown in Figure 3 for H460 NSCLC and TE2 esophageal cancer cells. Similar findings were also noted with other cultured NSCLC and esophageal cancer cell lines (data not shown).

\section{LY-Mediated Suppression of NF- $\kappa B$ Activity in NSCLC and Esophageal Cancer Cells}

Activated (phosphorylated) Akt stimulates the NF- $\kappa \mathrm{B}$ by degrading $\mathrm{I} \kappa \mathrm{B}$ (the natural inhibitor of NF- $\kappa \mathrm{B}$ ) and enhancing the transcriptional activity of the p65/RelA subunit of the NF- $\kappa$ B complex. ${ }^{10-14}$ Active NF- $\kappa \mathrm{B}$, in turn, up-regulates the expression of antiapoptotic proteins cIAP1, cIAP2, and BclXL. Further analysis of the effect of LY treatment on the levels of phosphorylated Akt, and those linking to the $\mathrm{NF}-\kappa \mathrm{B}$ pathway (I $\kappa \mathrm{B}$, cIAP1, cIAP2, and BclXL) in representative NSCLC cells H460 and H322, and esophageal cancer cells SKGT5 and TE2 is shown in Figure 4, A. In addition to suppressing constitutive activation of Akt (re- duction of phosphorylated Akt), LY treatment also resulted in dose-dependent elevation of $\mathrm{I} \kappa \mathrm{B}$ levels and reduction of NF- $\kappa \mathrm{B}-$ dependent antiapoptotic proteins cIAP1, cIAP2 (either one or both), and BclXL.

Transcriptional activity of NF- $\kappa \mathrm{B}$ in tumor cells was quantitatively evaluated by using the reporter plasmid NF$\kappa \mathrm{B}$-Luc. Preliminary experiments were performed using H460 and H322 cells to define the kinetics of LY-mediated inhibition of NF- $\kappa \mathrm{B}$ activity. Treating these cells that were transiently transfected with the reporter plasmid with LY $(10,20$, and $40 \mu \mathrm{mol} / \mathrm{L})$ resulted in significant treatment duration-dependent and dose-dependent inhibition of $\mathrm{NF}-\kappa \mathrm{B}$ transcriptional activity. NF- $\kappa \mathrm{B}$ activity started to decrease as early as 6 hours after the initiation of LY treatment and became profound after 18 hours of exposure to this PI3K inhibitor (data not shown). In subsequent experiments, NF- $\kappa$ B activity of cells treated with LY was evaluated after 18 hours of drug treatment. LY caused significant dose-dependent reduction of NF- $\kappa \mathrm{B}$ transcriptional activity in all 6 cell lines evaluated. The magnitude of inhibition of NF- $\kappa \mathrm{B}$ activity ranged from $20 \%$ to $40 \%$ at 10 $\mu \mathrm{mol} / \mathrm{L}$ of $\mathrm{LY}$ to as high as $60 \%$ to $80 \%$ at $40 \mu \mathrm{mol} / \mathrm{L}$ of LY (Figure 4, B). 
H460
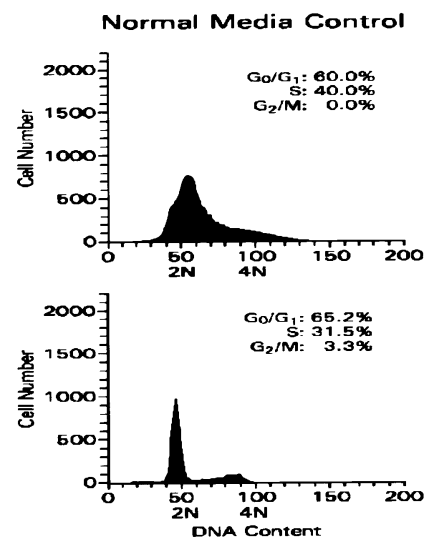

TE2
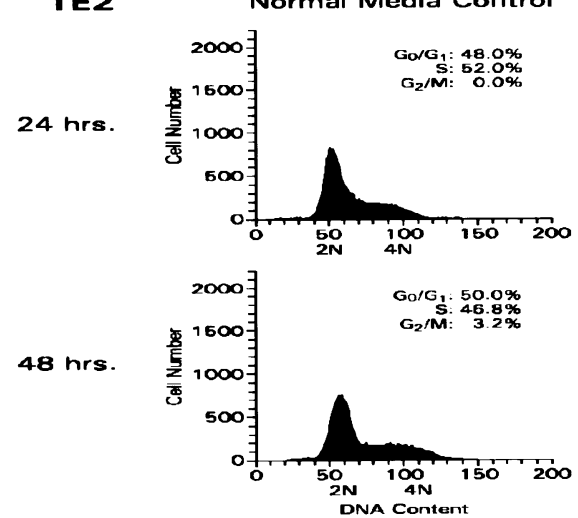
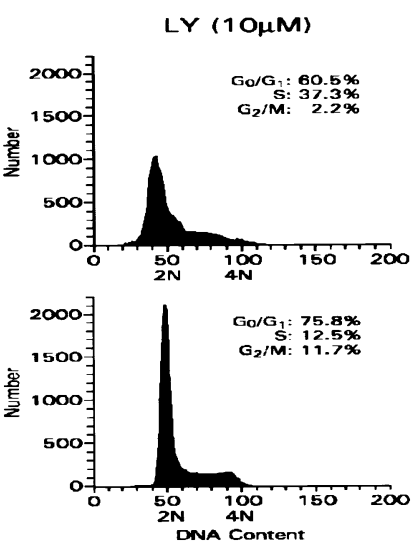

LY (1OHM)
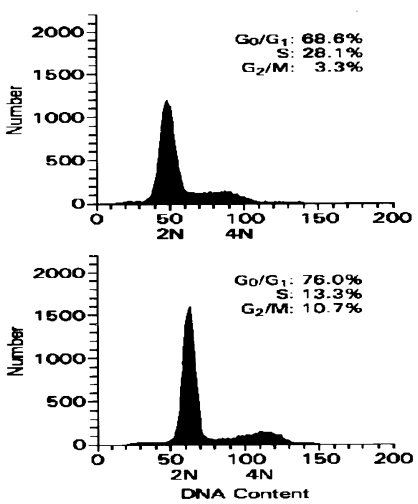
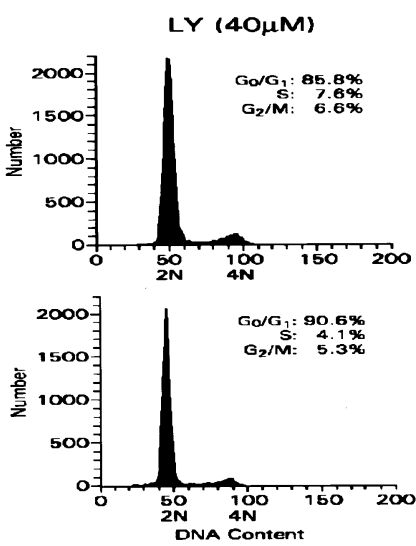

LY (40 MM)
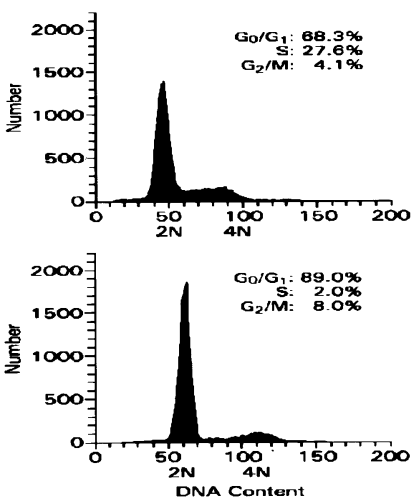

Figure 3. Dose- and time-dependent LY-mediated cell-cycle arrest at G0/G1 checkpoint in H460 NSCLC and TE2 esophageal cancer cells in vitro. Cell-cycle analysis was performed using propidium iodide staining and flow cytometry.

Enhancement of Paclitaxel Cytotoxicity by LY in NSCLC and Esophageal Cancer Cells In Vitro Treating NSCLC or esophageal cancer cells with paclitaxel for 90 minutes resulted in significant dose-dependent inhibition of cell proliferation in vitro. Intrinsic cellular sensitivity to paclitaxel cytotoxicity varied between cell lines with paclitaxel $\mathrm{IC}_{50}$ values ranging from 210 to $940 \mathrm{nmol} / \mathrm{L}$. Subsequent exposure of paclitaxel-treated cells to LY (10-40 $\mu \mathrm{mol} / \mathrm{L})$ resulted in further reduction of cell viability, the magnitude of which exceeded the mild growthinhibitory effect of LY alone, particularly at low concentrations of paclitaxel $(16-250 \mathrm{nmol} / \mathrm{L})$, suggestive of a synergistic drug combination effect (Figure 5). This was further demonstrated by estimating paclitaxel $\mathrm{IC}_{50}$ values of cells treated with paclitaxel + LY combinations. There was a 4- to more than 20-fold reduction of paclitaxel $\mathrm{IC}_{50}$ values in cells treated with paclitaxel + LY compared with the values of cells treated with paclitaxel alone (Figure 5). Paclitaxel treatment $(50-500 \mathrm{nmol} / \mathrm{L})$ was associated with activation of the PI3K/Akt pathway as indicated by elevated phosphorylated Akt levels that were profoundly suppressed by subsequent exposure to the PI3K inhibitor LY (40 $\mu \mathrm{mol} / \mathrm{L}$ ) (Figure $6, A$ ). Such elevations of phosphorylated Akt levels were paralleled with increased NF- $\kappa$ B transcriptional activity that was also suppressed by LY treatment (Figure 6, B). More important, cells treated with this drug combination were observed to undergo significant apoptosis even when treated at concentrations of paclitaxel or LY that induced only minor degrees of programmed cell death as detected by the TUNEL-based ApoBrdU assay (Figure 6, C).

\section{BAY and BAY-Mediated Enhancement of Paclitaxel- Induced Apoptosis}

LY-mediated enhancement of paclitaxel sensitivity was paralleled by its ability to down-regulate NF- $\kappa$ B activity. Subsequent experiments were performed to investigate the role of NF- $\kappa \mathrm{B}$ on paclitaxel sensitivity in cultured lung and esophageal cancer cells. Direct inhibition of NF- $\kappa \mathrm{B}$ was achieved by BAY, a potent inhibitor of I $\kappa \mathrm{K}$. Figure 7, A indicates significant dose-dependent inhibition of NF- $\kappa \mathrm{B}$ transcription activity by BAY in lung and esophageal cancer 

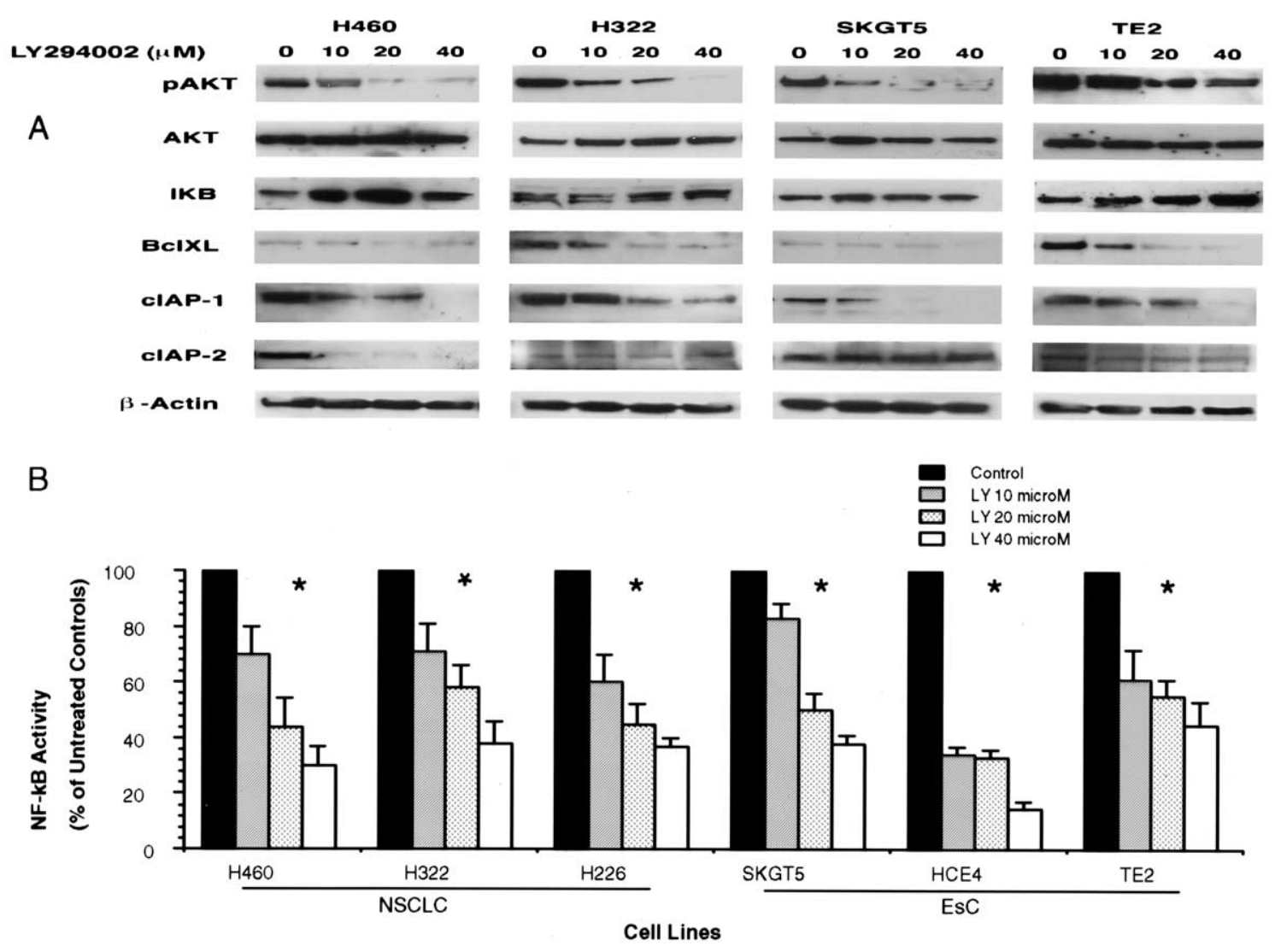

Figure 4. A, LY-mediated dose-dependent reduction of phosphorylated Akt levels in H322 and H460 NSCLC cells and SKGT5 and TE2 esophageal cancer cells was paralleled with increase of $I_{\kappa} B$ levels and reduced expression of NF- $\kappa$ B-dependent antiapoptotic proteins cIAP1, cIAP2, and BcIXL. B, LY-mediated dose-dependent suppression of intrinsic NF- $\kappa$ B activity in cultured NSCLC and esophageal cancer cells as determined by the NF- $\kappa$ B-Luciferase reporter system. Luciferase activity in LY-treated cells was expressed as percentages of activity of untreated control cells. Data are expressed as mean \pm SD of 3 independent experiments $\left({ }^{*} P<.001-P=.004\right.$ vs controls).

cell lines in vitro. The magnitude of inhibition varied between cell lines, ranging from $40 \%$ to $90 \%$ at $20 \mu \mathrm{mol} / \mathrm{L}$ of BAY. Direct inhibition of NF- $\kappa$ B by BAY in cells treated with sublethal doses of paclitaxel resulted in massive induction of apoptosis, matching (as in H322 and TE2 cells) or even exceeding (as in H460 and SKGT5 cells) the degrees of apoptosis induced by paclitaxel + LY (Figure 7, B).

\section{Discussion}

PI3K has recently been identified as a critical intracellular component downstream of growth factor receptor signaling. Aberrant PI3K function has been implicated in diverse pathologic conditions including diabetes mellitus and cancer. $^{3}$ Activation of PI3K is a function of growth factormediated activation and phosphorylation of its membrane receptor and the oncoprotein K-Ras. ${ }^{3}$ Overexpression of growth factors (members of the EGFR superfamily, insulinlike growth factor receptors, and receptors for hepatocyte growth factor/scatter factor) or mutation of K-Ras is very common in cancers, including those of the lung and the esophagus. ${ }^{2}$ Cancer cells with high levels of PI3K activation exhibit enhanced resistance to cytotoxic stress induced by serum deprivation or exposure to chemotherapeutic agents. ${ }^{3}$ PI3K transmits its signal through activation of Akt, which in turn phosphorylates and thereby modulates the function of numerous target proteins, including $\mathrm{I} \kappa \mathrm{K}$ and NF- $\kappa \mathrm{B}$ p65/ RelA subunit (to activate the NF- $\kappa$ B pathway), ${ }^{11-15}$ caspase 9 and Bad (to inhibit proapoptotic activity), ${ }^{16,17}$ and $\mathrm{p} 21$ or p27 (to suppress cell-cycle regulation activity). ${ }^{18,19}$ Because of their strategic roles in modulating growth and survival signal transduction cascades, PI3K and Akt are attractive molecular targets for cancer therapy. The availability of pharmacologic inhibitors of PI3K such as LY or Wortmannin greatly facilitates the molecular analysis of pathophysiologic roles of PI3K/Akt signaling in cancer cells, particularly with respect to its influence on chemosensitivity and resistance. 

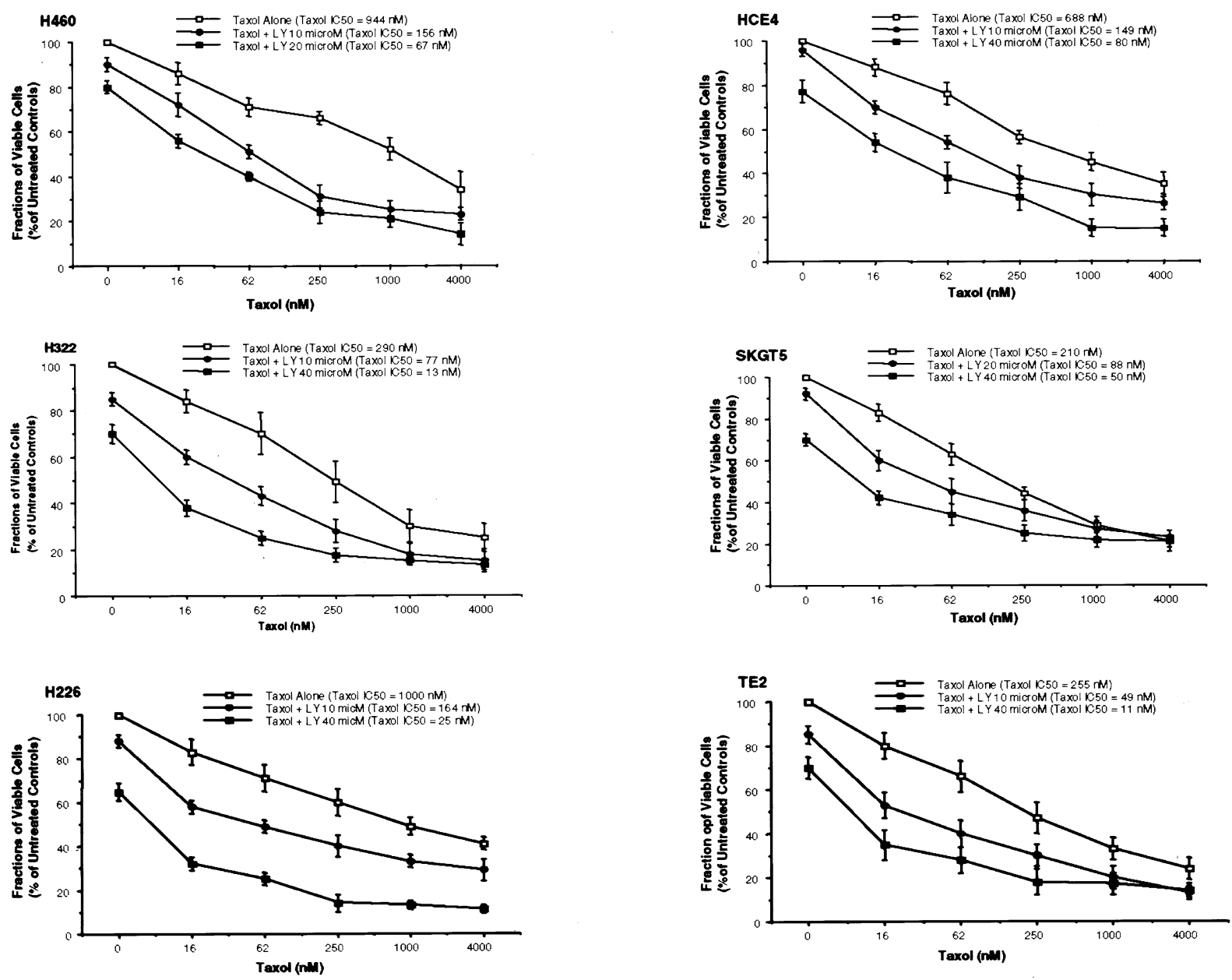

Figure 5. Supra-additive enhancement of cytotoxicity mediated by the Taxol + LY combinations. Although LY induced mild reduction of cell proliferation, exposure of Taxol-treated cells to LY resulted in further reduction of cell viability that exceeded the growth-inhibitory effect mediated by LY. Cultured cancer cells were treated with varying doses of Taxol for 90 minutes, followed by exposure to $L Y(10,20$, or $40 \mu \mathrm{mol} / \mathrm{L}) 12$ hours later. Viable cells were quantitated by MTT assay 72 hours after the onset of Taxol treatment. Data are expressed as mean \pm SD of 4 independent experiments.

Our data indicate that cultured lung and esophageal cancer cells constitutively expressed high levels of phosphorylated (activated) Akt and that LY-mediated profound reduction of activated Akt in these cells coincided with potent sensitization of treated cells to paclitaxel, in keeping with previous observations. ${ }^{5,8}$ However, evidence was lacking regarding the molecular mechanism of this LY-mediated salutary effect. Inhibition of PI3K/Akt signaling modulates many distinct cellular proteins, all of which participate in the apoptotic machinery. Any one of them, alone or in combination with others, may be responsible for the chemosensitization aspect of PI3K/Akt inhibition. Of all the downstream targets of Akt, the NF- $\kappa \mathrm{B}$ pathway deserves further investigation as an intermediary step mediating survival and chemoresistance function for PI3K/Akt. High levels of NF- $\kappa$ B activity have been linked to chemoresistance in breast cancer, which could be reversed by inhibition of NF- $\kappa \mathrm{B}$ through overexpression of $\mathrm{I} \kappa \mathrm{B}$ gene by genetic manipulation or pharmacologic inhibitors. ${ }^{20,21}$ Our data indicate a correlation between LY-mediated suppression of $\mathrm{NF}-\kappa \mathrm{B}$ transcription activity plus NF- $\kappa \mathrm{B}-$ regulated antiapoptotic proteins and LY-dependent sensitization to paclitaxel. Our data also indicate that direct inhibition of NF- $\kappa \mathrm{B}$ by BAY synergistically induced profound apoptosis in paclitaxel-treated lung and esophageal cancer cells. These circumstantial pieces of evidence indicate that LY-mediated suppression of NF- $\kappa \mathrm{B}$ activity actually participates in the process of chemosensitization mediated by PI3K inhibition. Confirmatory experiments using similar cell lines that are genetically engineered to express constitutively activated 

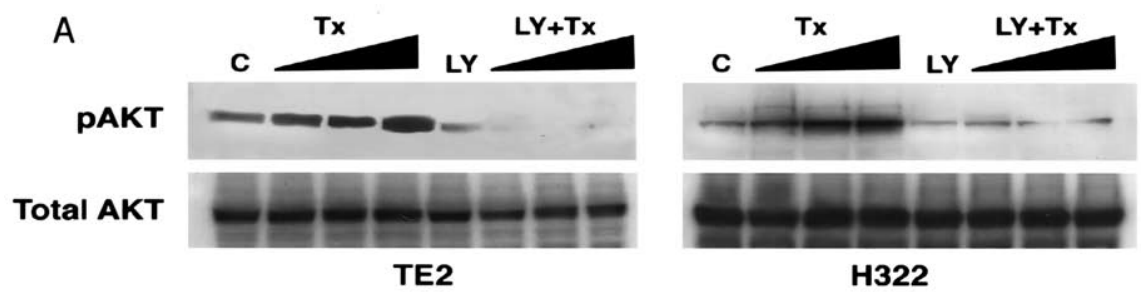

B
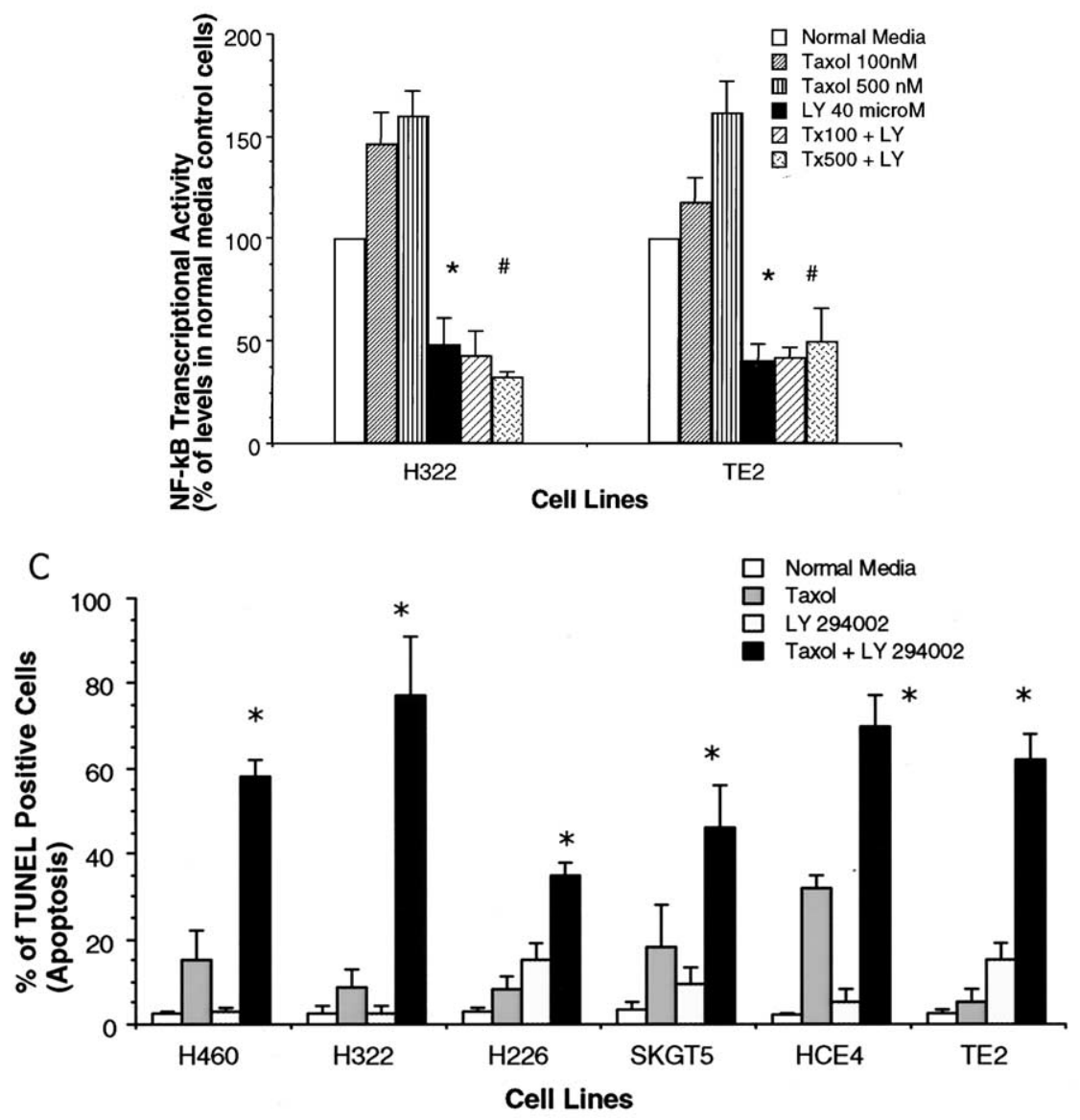

Figure 6. Activation of Akt (increased phosphorylated Akt levels) (A) and significant elevation of NF- $\kappa$ B transcriptional activity (as determined by NF- $\kappa$ B Luciferase reporter system) (B) in H322 NSCLC and TE2 esophageal cancer cells treated with increasing concentrations of Taxol $(50,100$, or $500 \mathrm{nmol} / \mathrm{L})$ was totally suppressed by PI3K inhibitor LY (40 $\mu \mathrm{mol} / \mathrm{L})$. Mean \pm SD; 3 independent experiments $\left(^{*} P=.012\right.$ vs controls, $\# P<.001$ vs Taxol-treated cells). The combinations of Taxol and LY synergistically induced apoptosis in NSCLC and esophageal cancer cells (C). Cells were sequentially treated with Taxol and LY for 60 hours before harvest and assayed for DNA fragmentation of apoptosis using the TUNEL-based ApoBrdU technique. Data are expressed as mean \pm SD of 3 independent experiments $\left({ }^{*} P<.001-P=.007\right.$ of Taxol + LY vs Taxol alone or LY alone). TUNEL, Terminal deoxynucleotide transferase-mediated dUTP nick-end labeling.

PI3K and the dominant negative mutant of $\mathrm{I} \kappa \mathrm{K}$ are in progress to conclusively define the role of NF- $\kappa \mathrm{B}$ as the intermediary step in the process of LY-mediated chemosensitization in cancer cells relative to cultured primary normal epithelia or fibroblasts.

\section{Conclusion}

Inhibition of the PI3K/Akt survival signal transduction pathway enhances paclitaxel-mediated cytotoxicity in cultured lung and esophageal cancer cells in vitro. The NF- $\kappa \mathrm{B}$ pathway, which is down-regulated by the PI3K 


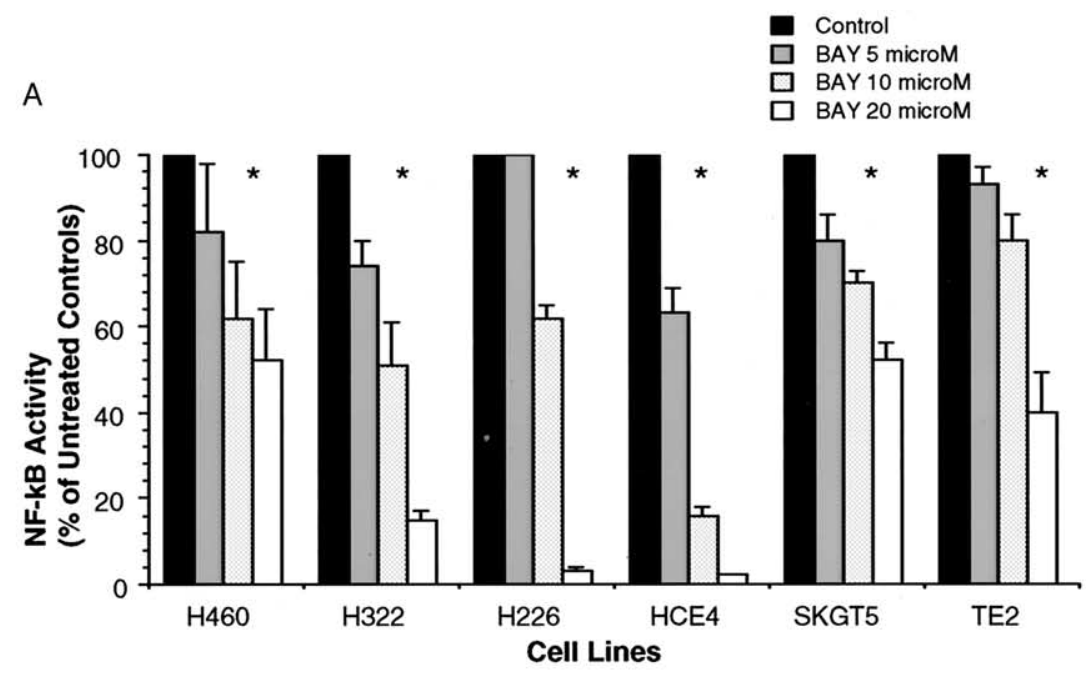

B
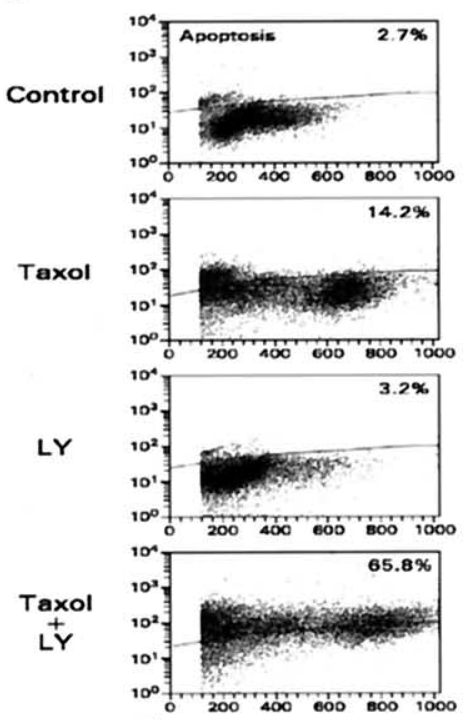

BAY

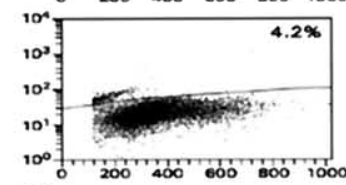

Taxol
BÁ

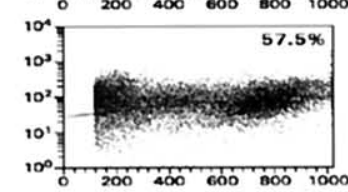

H46O
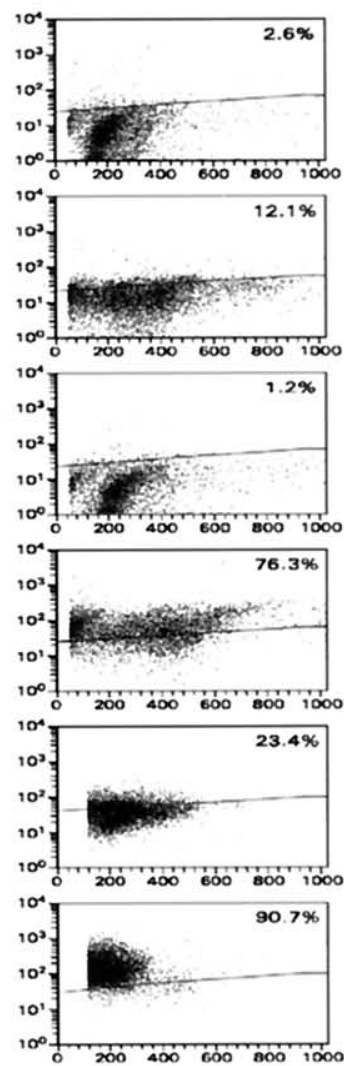

SKGT5
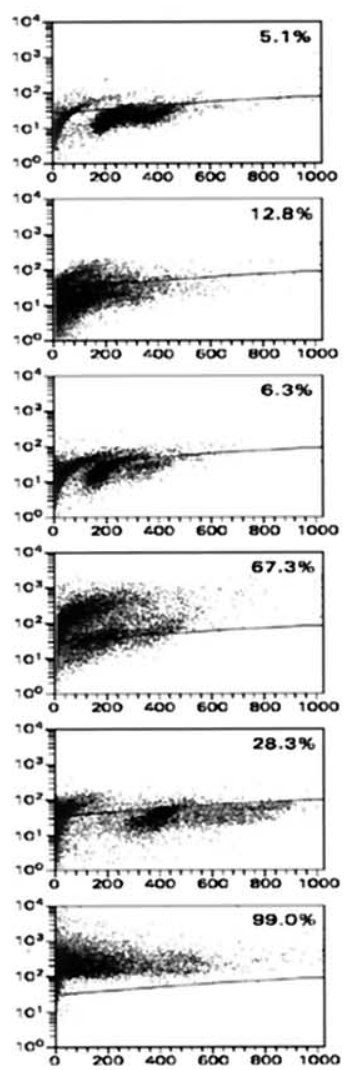
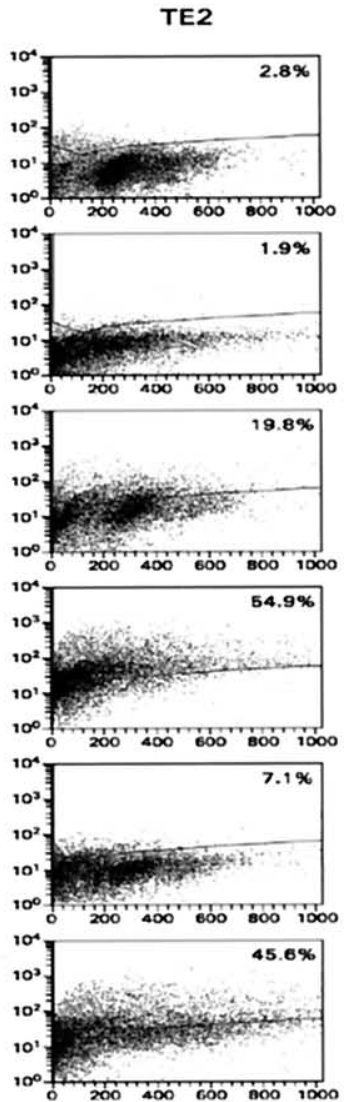

Figure 7. A, BAY, through direct inhibition of IкK, also suppressed intrinsic NF- $\kappa$ B activity in NSCLC and esophageal cancer cells. Data are expressed as mean \pm SD of 4 independent experiments $\left({ }^{*} P<.001-P=.013\right.$ vs controls). B, This was paralleled with an enhancement of the magnitude of apoptosis in cells treated with the Taxol + BAY combination. Representative data of 3 independent experiments that yielded similar results are shown here.

inhibitor LY and inhibition of which enhances paclitaxel sensitivity, seems to be a critical intermediary step connecting PI3K/Akt with the cellular process of chemosensitivity and resistance. The findings of this study provide the rationale for further preclinical studies evaluating the potential efficacy of anticancer therapeutic strategies targeting components of the PI3K/Akt signaling pathway. 
We acknowledge the superb assistance of Mr Arnold Mixon and Mr Shawn Farid of the Flow Cytometry Laboratory Core Facility, Surgery Branch, in performing cell-cycle analysis. We also thank Dr Steve Finkenstein and Mr Donald E. White for their help in performing statistical analysis of the data.

\section{References}

1. Bunn PA Jr, Kelly K. New chemotherapeutic agents prolong survival and improve quality of life in non-small cell lung cancer: a review of the literature and future directions. Clin Cancer Res. 1998;4:1087-100.

2. Schrump DS, Nguyen DM. Targets for molecular intervention in multistep pulmonary carcinogenesis. World J Surg. 2001;25:174-83.

3. Datta SR, Brunet A, Greenberg ME. Cellular survival: a play in three Akts. Genes Dev. 1999;13:2905-27.

4. Cantley LC. The phosphoinositide 3-kinase pathway. Science. 2002; 296:1655-7.

5. Hu L, Hofmann J, Lu Y, Mills GB, Jaffe RB. Inhibition of phosphatidylinositol 3'-kinase increases efficacy of paclitaxel in in vitro and in vivo ovarian cancer models. Cancer Res. 2002;62:1087-92.

6. Ng SSW, Tsao MS, Chow S, Hedley DW. Inhibition of phosphatidylinositide 3-kinase enhances gemcitabine-induced apoptosis in human pancreatic cancer cells. Cancer Res. 2000;60:5451-5.

7. Ng SSW, Tsao MS, Nicklee T, Hedley DW. Wortmannin inhibits pkb/akt phosphorylation and promotes gemcitabine antitumor activity in orthotopic human pancreatic cancer xenografts in immunodeficient mice. Clin Cancer Res. 2001;7:3269-75.

8. Page C, Lin HJ, Jin Y, Castle VP, Nunez G, Huang M, et al. Overexpression of Akt/AKT can modulate chemotherapy-induced apoptosis. Anticancer Res. 2000;20:407-16.

9. Brognard J, Clark AS, Ni Y, Dennis PA. Akt/protein kinase B is constitutively active in non-small cell lung cancer cells and promotes cellular survival and resistance to chemotherapy and radiation. Cancer Res. 2001;61:3986-97.

10. Pierce JW, Schoenleber R, Jesmok G, Best J, Moore SA, Collins T, et al. Novel inhibitors of cytokine-induced IkappaBalpha phosphorylation and endothelial cell adhesion molecule expression show antiinflammatory effects in vivo. J Biol Chem. 1997;272:21096-103.

11. Madrid LV, Wang CY, Guttridge DC, Schottelius AJ, Baldwin AS Jr, Mayo MW. Akt suppresses apoptosis by stimulating the transactivation potential of the RelA/p65 subunit of NF-kappaB. Mol Cell Biol. 2000;20:1626-38.

12. Sizemore N, Leung S, Stark GR. Activation of phosphatidylinositol 3-kinase in response to interleukin-1 leads to phosphorylation and activation of the NF-kappaB p65/RelA subunit. Mol Cell Biol. 1999; 19:4798-805.

13. Sizemore N, Lerner N, Dombrowski N, Sakurai H, Stark GR. Distinct roles of the Ikappa B kinase alpha and beta subunits in liberating nuclear factor kappa B (NF-kappa B) from Ikappa B and in phosphorylating the p65 subunit of NF-kappa B. J Biol Chem. 2002;277:3863-9.

14. Romashkova JA, Makarov SS. NF-kappaB is a target of AKT in anti-apoptotic PDGF signaling. Nature. 1999;401:86-90.

15. Ozes ON, Mayo LD, Gustin JA, Pfeffer SR, Pfeffer LM, Donner DB. NF-kappaB activation by tumour necrosis factor requires the Akt serine-threonine kinase. Nature. 1999;401:82-5.

16. Datta SR, Dudek H, Tao X, Masters S, Fu H, Gotoh Y, et al. Akt phosphorylation of BAD couples survival signals to the cell-intrinsic death machinery. Cell. 1997;91:231-41.

17. Cardone MH, Roy N, Stennicke HR, Salvesen GS, Franke TF, Stanbridge E, et al. Regulation of cell death protease caspase- 9 by phosphorylation. Science. 1998;282:1318-21.

18. Li Y, Dowbenko D, Lasky LA. AKT/PKB phosphorylation of p21Cip/ WAF1 enhances protein stability of p21Cip/WAF1 and promotes cell survival. J Biol Chem. 2002;277:11352-61.

19. Shin I, Yakes FM, Rojo F, Shin NY, Bakin AV, Baselga J, et al. $\mathrm{PKB} / \mathrm{Akt}$ mediates cell-cycle progression by phosphorylation of p27(Kip1) at threonine 157 and modulation of its cellular localization. Nat Med. 2002;8:1145-52.

20. Nakshatri H, Bhat-Nakshatri P, Martin DA, Goulet RJ Jr, Sledge GW Jr. Constitutive activation of NF-kappaB during progression of breast cancer to hormone-independent growth. Mol Cell Biol. 1997;17:362939.

21. Patel NM, Nozaki S, Shortle NH, Bhat-Nakshatri P, Newton TR, Rice $\mathrm{S}$, et al. Paclitaxel sensitivity of breast cancer cells with constitutively active NF-kappaB is enhanced by IkappaBalpha super-repressor and parthenolide. Oncogene. 2000;19:4159-69.

\section{Discussion}

Dr David A. Jones (Charlottesville, $\mathrm{Va}$ ). Did you look at kappa B transcriptional activation with Luciferase in one of your slides? Was the control just no treatment at all or was the control actually with paclitaxel?

Dr Nguyen. NF- $\kappa \mathrm{B}$ transcriptional activity was evaluated by using NF- $\kappa \mathrm{B}-$ Luciferase reporter plasmid assays. The controls for these assays were cells incubated in $10 \%$ fetal calf serum RPMI without any drug treatment at all.

Dr Jones. So do you have any evidence that paclitaxel either activated Akt or activates NF- $\kappa \mathrm{B}$ ?

Dr Nguyen. As shown by the Western blot of phosphorylated Akt in NSCLC and esophageal cancer cells treated with increasing concentrations of paclitaxel, paclitaxel exposure resulted in a dosedependent increase in phosphorylated Akt levels without affecting total Akt levels, and LY treatment abrogated this phosphorylated Akt increase, indicating that there was activation of the Akt pathway probably through the PI3K pathway. With regard to paclitaxel effect on NF- $\kappa$ B transcriptional activity, we had some preliminary data and are in the process of substantiating the observations that there was elevation of NF- $\kappa \mathrm{B}$ transcriptional activity after paclitaxel treatment.

Dr Jones. I think that is an important question. We have been able to show that chemotherapy activates NF- $\kappa \mathrm{B}-$ dependent transcription, and one of the mechanisms of chemoresistance is activating the cell survival pathway. But I didn't know whether you think paclitaxel actually activates Akt, being that it is upstream of NF- $\kappa$ B. Do you think Akt is activated by some type of cell membrane receptor or a change in the redox status of the cell or do you think that this is just true and unrelated, meaning chemotherapy does not activate Akt?

Dr Nguyen. That is an interesting comment. The current focus of our laboratory at the moment is to decipher the actual intracellular signaling of PI3K/Akt and NF- $\kappa \mathrm{B}$ after paclitaxel treatment. It is conceivable that as part of a stress response, there is upregulation of phenotypic expression or function of growth receptors, notably EGFR, which provides the upstream signaling for the PI3K/Akt axis after exposure to cytotoxic chemotherapeutics. There are reports in the literature demonstrating that there was activation of EGFR-mediated signaling after paclitaxel exposure, and this formed the basis for combining paclitaxel with anti-EGFR therapy strategies. I have no data on the role of oxygen free radicals as a putative mechanism for $\mathrm{NF}-\kappa \mathrm{B}$ activation or Akt activation in paclitaxel-treated cells.

Dr Steven J. Mentzer (Boston, Mass). You just have cell viability, you don't have cell proliferation or cell cycle. What does your inhibitor do to the cell cycle in these cell lines?

Dr Nguyen. In the full article, I have the diagram showing that LY actually induces cell-cycle arrest at the G0/G1 checkpoint.

Dr Mentzer. So it isn't just a population dynamics issue when you are selecting? 
Dr Nguyen. No, I think it is more than just a perturbation of cell cycle. I think it has something to do with cancer cells' survival response to stress.

Dr David H. Harpole, Jr (Durham, NC). Could you go back to the slide with the graphs of paclitaxel showing the suppressor at different doses? There was something that was a little confusing to me.

If I look at the top panels, at the zero time point, it looks like the fractured cell viability is actually decreased. Those lines are almost parallel. So what I am trying to say is that by looking at them myself, I can't really see that there's a difference in the top, middle, and lower panels with respect to the paclitaxel kill, if you normalize them all at zero time points to the same baseline. Does that make sense? Because the 3 lines are parallel to each other, I think what you are showing is the effect of giving your agent, but I am not sure that it shows a dependence on paclitaxel.

Dr Nguyen. Right. I do see what you mean. I had to normalize LY-treated cells alone to calculate paclitaxel $\mathrm{IC}_{50}$ values (indicative of paclitaxel effect in LY-treated cells with exclusion of LY mild growth inhibitory effect). These graphs are not to scale, so that's why they look like that.

Dr Harpole. All right. That explains it. Because at first it didn't seem to make sense.

Dr Nguyen. Right. Because if I put the graphs to scale, it is very hard to demonstrate the point. But once you normalize for that and calculate out the paclitaxel $\mathrm{IC}_{50}$ values, there is a clear enhancement of paclitaxel cytotoxicity by LY.

\section{Online-www.aats.org}

Now you can get The Journal of Thoracic and Cardiovascular Surgery online. The Journal online brings you faster delivery time, easy searching of current and back issues, links to PubMed, AATS, WTSA, and other important sites, and more. Visit the Journal online today.

\section{Receive tables of contents by e-mail}

To receive the tables of contents by e-mail, sign up through our Web site at http://www.mosby.com/jtcvs

Choose E-mail Notification

Simply type your e-mail address in the box and click the Subscribe button.

Alternatively, you may send an e-mail message to majordomo@mosby.com.

Leave the subject line blank and type the following as the body of your message: subscribe jtcvs_toc

You will receive an e-mail to confirm that you have been added to the mailing list.

Note that TOC e-mails will be sent out when a new issue is posted to the Web site. 